\title{
MULTI-CRITERIA OPTIMIZATION OF TURNING OF MARTENSITIC STAINLESS STEEL FOR SUSTAINABILITY
}

\author{
Sterpin Valic, G. ; Cukor, G. ; Jurkovic, Z. ${ }^{*} \&$ Brezocnik, M.* \\ *University of Rijeka, Faculty of Engineering, Vukovarska 58, 51000 Rijeka, Croatia \\ ${ }^{* *}$ University of Maribor, Faculty of Mechanical Engineering, Smetanova 17, 2000 Maribor, Slovenia \\ E-Mail: graciela.sterpin@riteh.hr, goran.cukor@riteh.hr, zoran.jurkovic@ riteh.hr, \\ miran.brezocnik@um.si
}

\begin{abstract}
A modern production strategy faces the increasing challenges of practicing green production without sacrificing machining performance. Thus, this paper compares emulsion cooling, minimum quantity lubrication without and with a Ranque-Hilsch vortex tube when turning martensitic stainless steel $\mathrm{X} 20 \mathrm{Cr} 13$. Experimental tests were organized corresponding to Taguchi orthogonal array $\mathrm{L}_{27}\left(3^{4}\right)$. The Taguchi based entropy weighted grey relational analysis was exploited to acquire the optimum combination of cutting speed, feed, depth of cut and cooling method that concurrently minimize surface roughness and tool life while maximizing material removal rate. The combination of minimum quantity lubrication with Ranque-Hilsch vortex tube confirmed to be the best cooling method. Hence, the use of classic metalworking fluids when turning martensitic stainless steels can be excluded, which is important for reducing environmental pollution and hence for machining sustainability.

(Received in August 2019, accepted in November 2019. This paper was with the authors 1 month for 1 revision.)
\end{abstract}

Key Words: Turning, Martensitic Stainless Steel, Sustainability, Multi-Criteria Optimization, Entropy Weighted Grey Relational Analysis, Taguchi Method

\section{INTRODUCTION}

The stainless steels are difficult-to-cut materials, so a high flow of metalworking fluid (MWF) should be used in their machining [1]. The MWF must provide cooling to prevent the overheating of surface being machined. In the event of overheating, which manifests itself as a nuanced coloration of machined surface, the corrosion resistance can be reduced. Also, the MWF must provide lubrication to decrease tool wear and to help flushing the chips [2].

The MWFs market is estimated to reach $\$ 9.74$ billion by 2020 , with an annual growth rate of $3.2 \%$ between 2015 and 2020 [3]. However, it is necessary to take into account the influence of MWFs not only on the machined part but also on the whole environment, primarily on the working surrounding. Namely, the MWFs contain large amounts of ingredients that are harmful to the environment and human health. Hence, they are classified as hazardous waste [4] and must be disposed of safely [5]. Nowadays, the costs of proper disposal of waste MWFs are higher than their purchase price.

Increasingly stringent environmental and occupational safety standards are a growing reason for replacing the use of conventional MWFs with alternative cooling and/or lubrication methods in machining, which is the reason for the development and application of so-called "green manufacturing". Its main goals are environmental protection, protection of workers, reduction of the use of MWFs and reduction of production costs achieved precisely by reducing the costs associated with MWFs. In this regard, minimum quantity lubrication (MQL) and chilled compressed air cooling are attracting increasing attention.

MQL involves consuming 5-50 millilitres of pure vegetable or synthetic oil per hour with almost no residue, while the usual wet machining consumes several litres of MWF per minute. The oil is dispersed in a stream of compressed air or, simply, in the form of an aerosol. More than 100 published papers in 2015 alone testify to the importance of MQL [6]. 
Chilled compressed air cooling is considered the cleanest and most environmentally friendly [7]. It is most often carried out by means of a counter-flow Ranque-Hilsch vortex tube (RHVT). Compressed air at ambient temperature tangentially enters the vortex tube where it splits into two swirling streams: inner colder and outer warmer, which is known as the Ranque-Hilsch effect. The cold air stream can reach the lowest temperature up to $-50{ }^{\circ} \mathrm{C}$ while the hot air stream can reach $100^{\circ} \mathrm{C}$. The RHVT is simple, inexpensive, compact, light and quiet to operate [8].

Investigations have shown the benefits of RHVT cooling in competition with the wet and dry machining. Ginting et al. [9] stated that the replacement of wet machining with RHVT cooling can save 80 cents apiece. Taha et al. [10] studied the effect of RHVT cooling on surface roughness and power consumption in dry turning. The results showed that this cooling solution reduces the cutting temperature. Liu et al. [11] achieved a temperature reduction of $57.1 \%$ using RHVT cooling compared to dry hard turning. Sarma and Dixit [12] found that at high cutting speeds dry turning compromises machined surface roughness due to rapid tool wear as opposed to RHVT cooling.

The main drawback of RHVT cooling is that there is no lubrication function while the main drawback of MQL is the poor cooling effect. Therefore, the researchers suggested combining them. Singh and Sharma [13] showed that when turning commercially pure titanium, the combination of MQL and RHVT compared to MQL alone decreases surface roughness at different combinations of cutting parameters. Deiab et al. [14] found that MQL with vegetable oil in combination with RHVT provides the lowest tool flank wear in turning titanium Ti-6Al-4V alloy compared to wet machining, dry machining, MQL with vegetable oil, RHVT cooling and cryogenic machining.

In order to obtain maximum cooling and lubrication effect, machining must be performed with optimal cutting parameters. Although the Taguchi method (TM) allows the study of multiple process responses simultaneously [15], it can only be used to optimize and evaluate the impact of each response individually (single criterion optimization). Sekulic et al. [16] found that TM is an efficient means of finding the optimal cutting parameters to reach minimum surface roughness or minimum main cutting force in high-pressure jet assisted turning of Inconel 718.

To solve multi-criteria optimization problems, TM can be used in combination with the grey relational analysis (GRA) first proposed by Deng [17]. GRA converts multi-criteria optimization problems into single criterion ones. It should be noted that there are fine differences with respect to combining, so that the grey based TM and Taguchi based GRA are distinguished. Thus, Puh et al. [18] used grey based TM, while Gupta and Sood [19] used Taguchi based GRA for multi-criteria optimization of turning. The accuracy and competence of prediction were confirmed for both methods.

In GRA different weight values are to be assigned to different criteria depending on their relative importance, which is completely left to the subjective decision-making of the researcher. This can be successfully overcome by applying the entropy measurement technique offered by Wen et al. [20]. Kumar et al. [21] tested entropy weighted grey based TM to optimize the cutting parameters for duplex turning of Inconel 718 by allocating the calculated entropy-weight to each criterion. Their results showed an improvement in the surface roughness, and primary and secondary cutting force in the optimal state.

There is also a lot of other literature available on optimizing cutting parameters in machining processes, including turning, milling and hybrid machining [22-25]. Some papers also discuss the cryogenic machining to reach the sustainability requirements [26, 27].

However, regarding the TM and grey based TM optimization of cutting parameters for turning martensitic stainless steels, only a few studies have been reported. The studies have focused on AISI 410, AISI 416 and AISI 440B workpiece materials and using of $\mathrm{TiCN} / \mathrm{Al}_{2} \mathrm{O}_{3}$, 
$\mathrm{Ti}(\mathrm{C}, \mathrm{N}, \mathrm{B}),(\mathrm{Ti}, \mathrm{Al}) \mathrm{N}$, ceramics and PcBN cutting tools in wet or dry machining conditions. The machining responses considered for single criterion or multi-criteria optimization problems were: surface roughness [28-34], tool wear [30, 32], machining time [34] and material removal rate $[29,34]$. Furthermore, very few papers are available dealing with the combination of MQL and RHVT, and none deals with martensitic stainless steels. Therefore, the goal set here is to inspect the impact of emulsion cooling and MQL without and with the RHVT when turning martensitic stainless steel X20Cr13 and test the Taguchi based entropy weighted GRA for multi-criteria turning process optimization.

\section{MATERIALS AND METHODS}

\subsection{Taguchi based entropy weighted grey relational analysis}

Optimization using the Taguchi based entropy weighted GRA is explained in more detail below.

\section{Step 1. Designing experiments}

This step involves: identifying the machining process responses and cutting parameters for inspection, determining the levels for the cutting parameters, and selecting the proper Taguchi orthogonal array according to which the experiments will be performed.

Step 2. Conducting experiments

Step 3. Normalization of responses

The normalized experimental results according to the lower-the-better (L-T-B) criterion can be calculated as:

$$
x_{i j}=\frac{\max y_{i j}-y_{i j}}{\max y_{i j}-\min y_{i j}}, \quad i=1, \ldots n, \quad j=1, \ldots, r
$$

where $y_{i j}$ are original data (the $i^{\text {th }}$ experimental result for the $j^{\text {th }}$ machining response). For the higher-the-better (H-T-B) criterion, the following expression can be used:

$$
x_{i j}=\frac{y_{i j}-\min y_{i j}}{\max y_{i j}-\min y_{i j}}, \quad i=1, \ldots, n, \quad j=1, \ldots, r
$$

Step 4. Grey relational coefficients (GRCs) calculation

GRCs can be determined as:

$$
\xi_{i j}=\frac{\zeta}{1-x_{i j}+\zeta}, \quad i=1, \ldots, n, \quad j=1, \ldots, r
$$

The distinguishing coefficient $\zeta$ generally has a value of 0.5 , i.e. $\zeta \in[0,1]$. GRC determines how close the actual normalized experimental results $x_{i j}$ are to the reference or the ideal target sequence $x_{0 j}=1$, and the larger the value of $\xi_{i j}$, the closer these two variables are.

Step 5. Entropy weighting

a) Sum of GRCs for each response

$$
D_{j}=\sum_{i=1}^{n} \xi_{i j}, \quad j=1, \ldots, r
$$

b) Normalized coefficient

$$
k=\frac{1}{\left(e^{0.5}-1\right) \times n}=\frac{1}{0.6487 \times n}
$$

c) Entropy of each response

$$
e_{j}=k \sum_{i=1}^{n} w_{e}\left(\frac{\xi_{i j}}{D_{j}}\right), \quad j=1, \ldots, r, \quad w_{e}(x)=x e^{(1-x)}+(1-x) e^{x}-1
$$


d) Sum of entropy

$$
E=\sum_{j=1}^{r} e_{j}
$$

e) Weight of each response

$$
w_{j}=\frac{1-e_{j}}{r-E}, \quad \sum_{j=1}^{r} w_{j}=1
$$

Step 6. Grey relational grades (GRGs) calculation

GRGs can be evaluated as:

$$
\Gamma_{i}=\sum_{j=1}^{r} w_{j} \xi_{i j}, \quad i=1, \ldots, n
$$

Step 7. Calculation of the Taguchi's signal-to-noise (S/N) ratio for GRGs

The higher $\Gamma_{i}$, the corresponding response is closer to the ideal one. Hence, the $S / N$ ratio for the higher-the-better (H-T-B) criterion should be used:

$$
S N_{i}=-10 \log \sum_{i=1}^{n} \frac{1}{\Gamma_{i}^{2}}
$$

Step 8. Analysis of experimental results

Here, the optimum levels of cutting parameters are detected on the basis of an analysis of $S / N$ ratios, and the significance of their influence is determined based on the analysis of the variance (ANOVA) of the $S / N$ ratios.

Step 9. Conducting of confirmation experiment

Once the optimal solution for cutting parameters is identified, the last effort is prediction and verification of the improvements in the machining responses. The expression for predicting the $S / N$ ratio is:

$$
S N_{o p t}=S N_{t}+\sum_{k=1}^{S}\left(S N_{k}-S N_{t}\right)
$$

where $S N_{t}$ is the total mean of $S / N$ ratios, $S N_{k}$ is the highest mean $S / N$ ratio for the cutting parameter and $s$ is the total number of cutting parameters with significant influence on the machining responses.

\subsection{The experimental procedure}

The material tested in the experiment was quenched and tempered martensitic stainless steel $\mathrm{X} 20 \mathrm{Cr} 13(0.236 \% \mathrm{C}, 11.97 \% \mathrm{Cr}, 0.299 \% \mathrm{Ni}, 0.683 \% \mathrm{Mn}, 0.352 \% \mathrm{Si}, 0.125 \% \mathrm{Mo}$, $0.023 \% \mathrm{~S}, 0.044 \% \mathrm{P}, 0.053 \% \mathrm{~V}, 0.07 \% \mathrm{Nb}, 0.195 \% \mathrm{Cu}, 85.85 \% \mathrm{Fe})$. The mechanical properties were as follows: yield strength $R_{p(0.2)}=750 \mathrm{MPa}$, tensile strength $R_{m}=881 \mathrm{MPa}$, and Brinell hardness $=272 \mathrm{HB}$.

The cutting speed $v_{c}$ in $\mathrm{m} / \mathrm{min}$, feed $f$ in $\mathrm{mm} / \mathrm{rev}$, depth of cut $a_{p}$ in $\mathrm{mm}$ and cooling condition (emulsion cooling, MQL, and MQL+RHVT) were selected as cutting parameters. The average surface roughness $R a$ in $\mu \mathrm{m}$, mean roughness depth $R z$ in $\mu \mathrm{m}$, tool life $T$ in min and material removal rate $\mathrm{MRR}=1000 \times v_{c} \times f \times a_{p}$ in $\mathrm{mm}^{3} / \mathrm{min}$ are considered as response parameters. The levels of cutting parameters are presented in Table I. The tests were organized corresponding to Taguchi orthogonal array $\mathrm{L}_{27}\left(3^{4}\right)$, Table II. The order in which the experiments were performed was the result of random selection using an Android-platform program Random Generator 5.0.1. 
Table I: Levels of cutting parameters.

\begin{tabular}{|c|c|c|c|}
\hline \multirow{2}{*}{ Parameter } & \multicolumn{3}{|c|}{ Level } \\
\cline { 2 - 4 } & 1 & 2 & 3 \\
\hline Cutting speed $v_{c}(\mathrm{~m} / \mathrm{min})$ & 260 & 290 & 320 \\
\hline Feed $f(\mathrm{~mm} / \mathrm{rev})$ & 0.3 & 0.35 & 0.4 \\
\hline Depth of cut $a_{p}(\mathrm{~mm})$ & 1 & 1.5 & 2 \\
\hline Cooling method $C$ & Emulsion & MQL & MQL+RHVT \\
\hline
\end{tabular}

Table II: Experimental layout for Taguchi orthogonal array $\mathrm{L}_{27}\left(3^{4}\right)$.

\begin{tabular}{|c|c|c|c|c|c|c|c|c|}
\hline \multirow{2}{*}{$\begin{array}{c}\text { Test } \\
\text { order }\end{array}$} & \multirow{2}{*}{ Test } & \multicolumn{7}{|c|}{ Parameters } \\
\hline & number & $v_{c}$ & $f$ & $v_{c} \times f$ & $a_{p}$ & $v_{c} \times a_{p}$ & $f \times a_{p}$ & $C$ \\
\hline 11 & 1 & 1 & 1 & 1 & 1 & 1 & 1 & 1 \\
\hline 20 & 2 & 1 & 1 & 1 & 2 & 2 & 2 & 2 \\
\hline 5 & 3 & 1 & 1 & 1 & 3 & 3 & 3 & 3 \\
\hline 1 & 4 & 1 & 2 & 2 & 1 & 1 & 2 & 2 \\
\hline 19 & 5 & 1 & 2 & 2 & 2 & 2 & 3 & 3 \\
\hline 23 & 6 & 1 & 2 & 2 & 3 & 3 & 1 & 1 \\
\hline 14 & 7 & 1 & 3 & 3 & 1 & 1 & 3 & 3 \\
\hline 26 & 8 & 1 & 3 & 3 & 2 & 2 & 1 & 1 \\
\hline 3 & 9 & 1 & 3 & 3 & 3 & 3 & 2 & 2 \\
\hline 21 & 10 & 2 & 1 & 2 & 1 & 2 & 1 & 2 \\
\hline 27 & 11 & 2 & 1 & 2 & 2 & 3 & 2 & 3 \\
\hline 6 & 12 & 2 & 1 & 2 & 3 & 1 & 3 & 1 \\
\hline 2 & 13 & 2 & 2 & 3 & 1 & 2 & 2 & 3 \\
\hline 4 & 14 & 2 & 2 & 3 & 2 & 3 & 3 & 1 \\
\hline 12 & 15 & 2 & 2 & 3 & 3 & 1 & 1 & 2 \\
\hline 16 & 16 & 2 & 3 & 1 & 1 & 2 & 3 & 1 \\
\hline 22 & 17 & 2 & 3 & 1 & 2 & 3 & 1 & 2 \\
\hline 25 & 18 & 2 & 3 & 1 & 3 & 1 & 2 & 3 \\
\hline 9 & 19 & 3 & 1 & 3 & 1 & 3 & 1 & 3 \\
\hline 10 & 20 & 3 & 1 & 3 & 2 & 1 & 2 & 1 \\
\hline 15 & 21 & 3 & 1 & 3 & 3 & 2 & 3 & 2 \\
\hline 17 & 22 & 3 & 2 & 1 & 1 & 3 & 2 & 1 \\
\hline 7 & 23 & 3 & 2 & 1 & 2 & 1 & 3 & 2 \\
\hline 24 & 24 & 3 & 2 & 1 & 3 & 2 & 1 & 3 \\
\hline 18 & 25 & 3 & 3 & 2 & 1 & 3 & 3 & 2 \\
\hline 13 & 26 & 3 & 3 & 2 & 2 & 1 & 1 & 3 \\
\hline 8 & 27 & 3 & 3 & 2 & 3 & 2 & 2 & 1 \\
\hline & & & & & & & & \\
\hline
\end{tabular}

The longitudinal turning experiments were conducted on the bars with a diameter of $80 \mathrm{~mm}$ and a length of $463 \mathrm{~mm}$. CNC lathe TU 360 Prvomajska, Seco DNMG 150608-MF-4 cutting inserts of TM 4000 grade (tungsten carbide), and a tool holder DDJNL 2525M15-M were used.

In wet machining, $5 \%$ emulsion (INA BU 7 concentrate) was employed. For MQL, the biodegradable oil LUB 200 was used.

The turning process in MQL and MQL+RHVC conditions is performed using an external unit VE1B-PB2_10 (manufactured by SKF) and a counter-flow vortex tube manufactured by EXAIR, model 3825 connected in one system. The system functions in such a way that the supply of compressed air at room temperature comes directly in front of the MQL unit where there are two ball valves that open/close the air flow to the MQL unit and RHVT, Fig. 1. In 
this way it is possible to apply either lubrication (MQL) or cooling (RHVT) or a combination thereof (MQL+RHVT). Also, a nozzle has been designed to allow micro-droplets from the MQL unit and chilled compressed air from the RHVT to be connected in one stream (single channel system) before entering the cutting zone, thus allowing for simultaneous lubrication and cooling. The nozzle model was printed using 3D Form 2 printer (manufactured by Formlabs), which operates on the principle of stereolithography using a laser device to obtain solid isotropic parts from a liquid photopolymer resin. The material of which the nozzle was made is a standard grey photoreactive resin, which is exquisite for capturing small details with high resolution and finishing and matte finish without the need for subsequent hardening.

The surface roughness measurements were made using a Hommel Tester T1000 profilometer (manufactured by JENOPTIK). To avoid possible mistakes due to re-clamping operation, the surface roughness parameters had been measured directly on the workpiece in the lathe. Also, to reduce deviation, the mean value of three measurements was adopted as a result of each experiment.

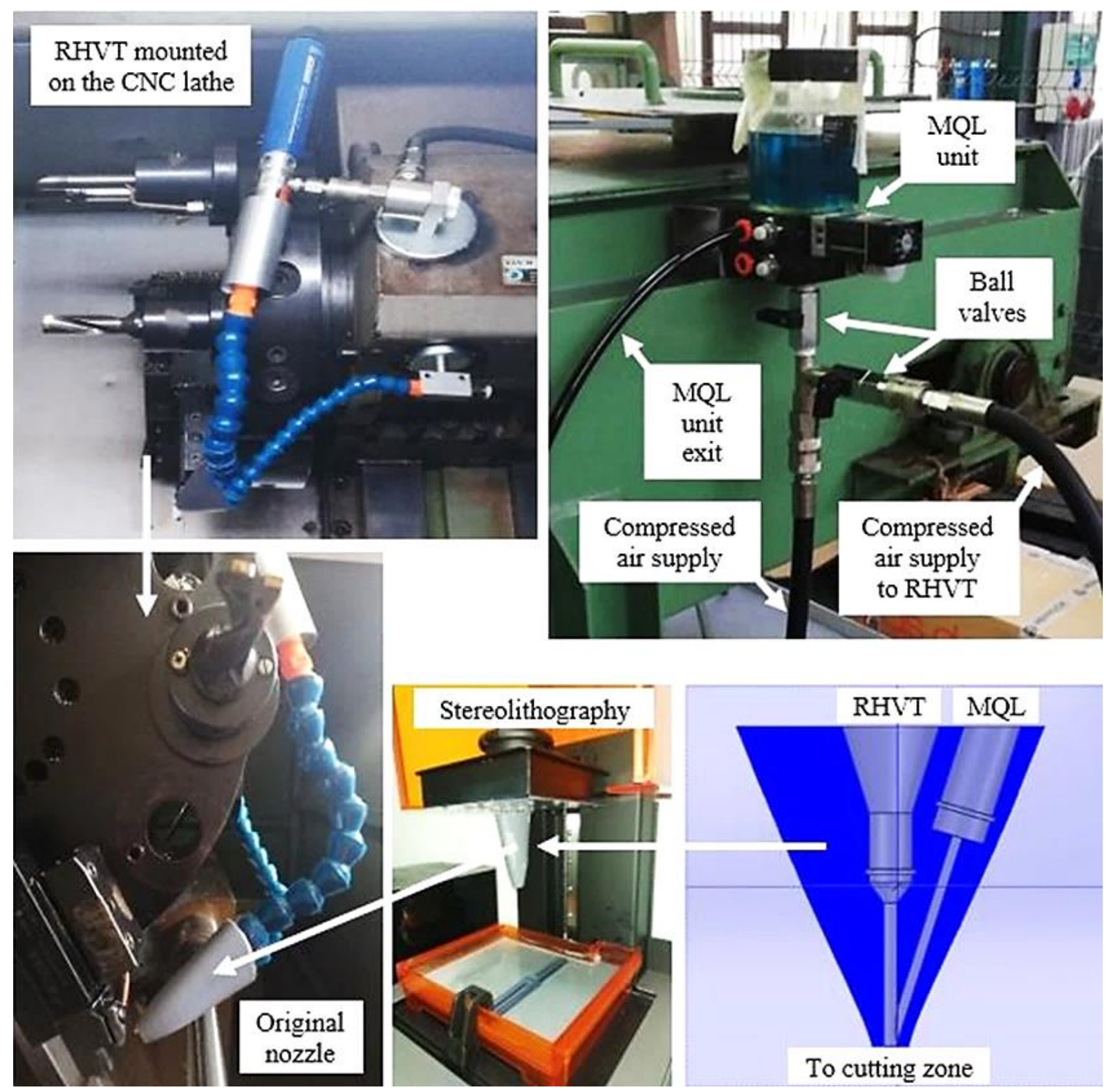

Figure 1: Set up of MQL unit, RHVT and MQL+RHVT with 3D printed original nozzle. 


\section{RESULTS AND DISCUSSION}

\subsection{Determination of the optimal cutting parameters}

In this work, an optimum combination of cutting parameters for $\mathrm{X} 20 \mathrm{Cr} 13$ martensitic stainless steel turning are obtained by using the Taguchi based entropy weighted GRA. The results and calculations are presented below.

Table III shows the experimental results and their normalized values. Also, grey relational coefficients, weight value for each machining response, rank and $S / N$ ratio for each calculated GRG are presented in Table IV. The experiment under No. 3 has the best combination of cutting parameters among 27 performed experiments since it has the highest $\Gamma_{i}$ value as depicted in Table IV.

The mean $S / N$ ratios calculated from Table IV taking the average of the $S / N$ ratios for each level of input cutting parameters individually, are presented in Table V. Besides, the total mean of the $S / N$ ratios for all 27 tests is given too. The optimal levels for cutting parameters can easily be obtained from Table V. For any cutting parameter, the optimum level is one with the maximal value of mean $S / N$ ratio. Therefore, the optimum combination is as follows: first level of cutting speed $v_{c}$, first level of feed $f$, third level of depth of cut $a_{p}$, and the MQL+RHVT cooling method. According to the results presented in Table V, the feed has the utmost influence on reducing the surface roughness parameters $R a$ and $R z$ and improving tool life $T$ and material removal rate $M R R$, and then cooling method, depth of cut and cutting speed. However, the exact contribution steel needs to be found.

Table III: Experimental results and normalized values: ideal sequence $(1,1,1,1)$.

\begin{tabular}{|c|c|c|c|c|c|c|c|c|}
\hline \multirow{2}{*}{$\begin{array}{c}\text { Test } \\
\text { number }\end{array}$} & \multicolumn{4}{|c|}{ Responses } & \multicolumn{4}{c|}{ Normalized values } \\
\cline { 2 - 8 } & $\begin{array}{c}R a \\
(\mu \mathrm{m})\end{array}$ & $\begin{array}{c}R z \\
(\mu \mathrm{m})\end{array}$ & $\begin{array}{c}T \\
(\mathrm{~min})\end{array}$ & $\begin{array}{c}M R R \\
\left(\mathrm{~mm}^{3} / \mathrm{min}\right)\end{array}$ & $\begin{array}{c}R a \\
\text { L-T-B }\end{array}$ & $\begin{array}{c}R z \\
\text { L-T-B }\end{array}$ & $\begin{array}{c}T \\
\text { H-T-B }\end{array}$ & $\begin{array}{c}M R R \\
\text { H-T-B }\end{array}$ \\
\hline 1 & 1.587 & 8.10 & 18.7 & 78000 & 0.63744 & 0.74462 & 1.00000 & 0.00000 \\
\hline 2 & 1.760 & 8.46 & 3.81 & 117000 & 0.38039 & 0.64785 & 0.17689 & 0.21910 \\
\hline 3 & 1.343 & 7.15 & 5.35 & 156000 & 1.00000 & 1.00000 & 0.26202 & 0.43820 \\
\hline 4 & 1.653 & 8.53 & 8.87 & 91000 & 0.53938 & 0.62903 & 0.45661 & 0.07303 \\
\hline 5 & 1.678 & 8.08 & 6.05 & 136500 & 0.50223 & 0.75000 & 0.30072 & 0.32865 \\
\hline 6 & 1.913 & 9.62 & 5.01 & 182000 & 0.15305 & 0.33602 & 0.24323 & 0.58427 \\
\hline 7 & 1.727 & 8.80 & 9.50 & 104000 & 0.42942 & 0.55645 & 0.49143 & 0.14607 \\
\hline 8 & 2.016 & 9.31 & 3.50 & 156000 & 0.00000 & 0.41935 & 0.15976 & 0.43820 \\
\hline 9 & 1.921 & 9.72 & 0.76 & 208000 & 0.14116 & 0.30914 & 0.00829 & 0.73034 \\
\hline 10 & 1.544 & 7.61 & 6.10 & 87000 & 0.70134 & 0.87634 & 0.30348 & 0.05056 \\
\hline 11 & 1.442 & 7.34 & 3.41 & 130500 & 0.85290 & 0.94892 & 0.15478 & 0.29494 \\
\hline 12 & 1.575 & 8.02 & 2.83 & 174000 & 0.65527 & 0.76613 & 0.12272 & 0.53933 \\
\hline 13 & 1.592 & 8.06 & 5.05 & 152250 & 0.63001 & 0.75538 & 0.24544 & 0.41713 \\
\hline 14 & 1.921 & 9.61 & 3.65 & 152250 & 0.14116 & 0.33871 & 0.16805 & 0.41713 \\
\hline 15 & 1.953 & 9.42 & 0.99 & 203000 & 0.09361 & 0.38978 & 0.02101 & 0.70225 \\
\hline 16 & 1.825 & 8.86 & 3.38 & 116000 & 0.28380 & 0.54032 & 0.15312 & 0.21348 \\
\hline 17 & 1.916 & 9.67 & 1.05 & 174000 & 0.14859 & 0.32258 & 0.02432 & 0.53933 \\
\hline 18 & 1.844 & 10.08 & 1.02 & 232000 & 0.25557 & 0.21237 & 0.02266 & 0.86517 \\
\hline 19 & 1.594 & 7.84 & 5.58 & 96000 & 0.62704 & 0.81452 & 0.27474 & 0.10112 \\
\hline 20 & 1.623 & 8.30 & 2.55 & 144000 & 0.58395 & 0.69086 & 0.10724 & 0.37079 \\
\hline 21 & 1.739 & 8.18 & 0.81 & 192000 & 0.41159 & 0.72312 & 0.01106 & 0.64045 \\
\hline 22 & 1.742 & 9.05 & 3.42 & 112000 & 0.40713 & 0.48925 & 0.15533 & 0.19101 \\
\hline 23 & 1.669 & 7.82 & 0.61 & 168000 & 0.51560 & 0.81989 & 0.00000 & 0.50562 \\
\hline 24 & 1.685 & 8.31 & 1.13 & 224000 & 0.49183 & 0.68817 & 0.02875 & 0.82022 \\
\hline 25 & 1.898 & 8.68 & 1.11 & 128000 & 0.17533 & 0.58871 & 0.02764 & 0.28090 \\
\hline 26 & 1.777 & 8.28 & 1.31 & 192000 & 0.35513 & 0.69624 & 0.03870 & 0.64045 \\
\hline 27 & 2.007 & 10.87 & 0.85 & 256000 & 0.01337 & 0.00000 & 0.01327 & 1.00000 \\
\hline & & & & & & & & \\
\end{tabular}


Sterpin Valic, Cukor, Jurkovic, Brezocnik: Multi-Criteria Optimization of Turning of ...

Table IV: Calculated grey relational grades.

\begin{tabular}{|c|c|c|c|c|c|c|c|}
\hline \multirow{2}{*}{$\begin{array}{c}\text { Test } \\
\text { number }\end{array}$} & \multicolumn{4}{|c|}{ Grey relational coefficients } & \multicolumn{3}{|c|}{ Grey relational grade } \\
\hline & $R a$ & $R z$ & $T$ & $M R R$ & $\Gamma$ & Rank & $\begin{array}{c}S / N \text { ratio } \\
\text { H-T-B }\end{array}$ \\
\hline 1 & 0.57967 & 0.66192 & 1.00000 & 0.33333 & 0.64374 & 2 & -3.82584 \\
\hline 2 & 0.44658 & 0.58675 & 0.37790 & 0.39035 & 0.45039 & 18 & -6.92824 \\
\hline 3 & 1.00000 & 1.00000 & 0.40388 & 0.47090 & 0.71868 & 1 & -2.86932 \\
\hline 4 & 0.52049 & 0.57407 & 0.47921 & 0.35039 & 0.48104 & 15 & -6.35642 \\
\hline 5 & 0.50112 & 0.66667 & 0.41692 & 0.42686 & 0.50288 & 11 & -5.97068 \\
\hline 6 & 0.37121 & 0.42956 & 0.39784 & 0.54601 & 0.43616 & 21 & -7.20714 \\
\hline 7 & 0.46704 & 0.52991 & 0.49575 & 0.36929 & 0.46550 & 17 & -6.64166 \\
\hline 8 & 0.33333 & 0.46269 & 0.37307 & 0.47090 & 0.40999 & 26 & -7.74443 \\
\hline 9 & 0.36796 & 0.41986 & 0.33519 & 0.64964 & 0.44316 & 19 & -7.06874 \\
\hline 10 & 0.62605 & 0.80172 & 0.41788 & 0.34496 & 0.54764 & 4 & -5.23010 \\
\hline 11 & 0.77268 & 0.90732 & 0.37169 & 0.41492 & 0.61663 & 3 & -4.19947 \\
\hline 12 & 0.59191 & 0.68132 & 0.36303 & 0.52047 & 0.53917 & 6 & -5.36543 \\
\hline 13 & 0.57472 & 0.67148 & 0.39855 & 0.46174 & 0.52661 & 7 & -5.57016 \\
\hline 14 & 0.36796 & 0.43056 & 0.37539 & 0.46174 & 0.40891 & 27 & -7.76744 \\
\hline 15 & 0.35552 & 0.45036 & 0.33807 & 0.62676 & 0.44268 & 20 & -7.07825 \\
\hline 16 & 0.41112 & 0.52101 & 0.37123 & 0.38865 & 0.42300 & 23 & -7.47328 \\
\hline 17 & 0.36998 & 0.42466 & 0.33883 & 0.52047 & 0.41348 & 25 & -7.67084 \\
\hline 18 & 0.40179 & 0.38831 & 0.33845 & 0.78761 & 0.47904 & 16 & -6.39252 \\
\hline 19 & 0.57277 & 0.72941 & 0.40808 & 0.35743 & 0.51691 & 9 & -5.73170 \\
\hline 20 & 0.54582 & 0.61794 & 0.35900 & 0.44279 & 0.49138 & 14 & -6.17165 \\
\hline 21 & 0.45939 & 0.64360 & 0.33581 & 0.58170 & 0.50512 & 10 & -5.93218 \\
\hline 22 & 0.45751 & 0.49468 & 0.37184 & 0.38197 & 0.42650 & 22 & -7.40166 \\
\hline 23 & 0.50792 & 0.73518 & 0.33333 & 0.50282 & 0.51980 & 8 & -5.68321 \\
\hline 24 & 0.49595 & 0.61589 & 0.33985 & 0.73554 & 0.54680 & 5 & -5.24341 \\
\hline 25 & 0.37745 & 0.54867 & 0.33959 & 0.41014 & 0.41896 & 24 & -7.55659 \\
\hline 26 & 0.43673 & 0.62207 & 0.34216 & 0.58170 & 0.49566 & 13 & -6.09634 \\
\hline \multirow[t]{3}{*}{27} & 0.33633 & 0.33333 & 0.33631 & 1.00000 & 0.50150 & 12 & -5.99457 \\
\hline & \multicolumn{4}{|c|}{ Weights } & & & \\
\hline & 0.249998 & 0.249969 & 0.250022 & 0.250011 & & & \\
\hline
\end{tabular}

Table V: Response table (means) for $S / N$ ratio.

\begin{tabular}{|c|c|c|c|c|}
\hline \multirow{2}{*}{ Level } & \multicolumn{4}{|c|}{ Cutting parameters } \\
\cline { 2 - 5 } & $v_{c}$ & $f$ & $a_{p}$ & $C$ \\
\hline 1 & $\mathbf{- 6 . 0 6 8 0 5}$ & $\mathbf{- 5 . 1 3 9 3 3}$ & -6.19860 & -6.55016 \\
\hline 2 & -6.30528 & -6.47538 & -6.47026 & -6.61162 \\
\hline 3 & -6.20126 & -6.95989 & $\mathbf{- 5 . 9 0 5 7 3}$ & $\mathbf{- 5 . 4 1 2 8 1}$ \\
\hline Max-Min & 0.23722 & 1.82056 & 0.56453 & 1.19881 \\
\hline Rank & 4 & 1 & 3 & 2 \\
\hline \multicolumn{5}{|l}{ Total mean of $S / N$ ratios $=-6.19153$} \\
\hline
\end{tabular}

\subsection{Analysis of variance (ANOVA)}

The aim of ANOVA is to identify the cutting parameters that notably influence the $S / N$ ratio. Also, it can be used to resolve the contribution of the change of cutting parameter to the machining response. The degrees of freedom $D F$, sum of squares $S S$, mean squares $M S$ (variance) and $F$-value (variance ratio) were calculated. Besides, for each parameter, the contribution $P C$ in percentages was determined too. The results are presented in Table VI. The $P C$ value shows the relative power of a parameter to decrease variation. The higher the $P C$ value, the more important is the contribution of cutting parameter change. It can be seen that the feed influences the most $(40.43 \%)$, followed by cooling method $(20.73 \%)$. The latter is very important information from the aspect of machining sustainability. Furthermore, the 
cutting speed, depth of cut and two-factorial interactions had no statistically significance on the $S / N$ ratios at the confidence level of $95 \%$ because their $F$-calculated values are less than $F_{0}$-tabulated values, so they can be neglected.

Table VI: ANOVA for $S / N$ ratio.

\begin{tabular}{|c|c|c|c|c|c|}
\hline & $\boldsymbol{D F}$ & $\boldsymbol{S S}$ & $\boldsymbol{M S}$ & $\boldsymbol{F}$ & $\boldsymbol{P C}(\%)$ \\
\hline$v_{c}$ & 2 & 0.25451 & 0.12726 & $0.20^{*}$ & 0.64 \\
\hline$f$ & 2 & 16.00261 & 8.00131 & 12.89 & 40.43 \\
\hline$a_{p}$ & 2 & 1.43479 & 0.71739 & $1.16^{*}$ & 3.62 \\
\hline$C$ & 2 & 8.20351 & 4.10176 & 6.61 & 20.73 \\
\hline$v_{c} \times f$ & 4 & 4.38894 & 1.09723 & $1.77^{*}$ & 11.09 \\
\hline$v_{c} \times a_{p}$ & 4 & 4.14836 & 1.03709 & $1.67^{*}$ & 10.48 \\
\hline$f \times a_{p}$ & 4 & 1.42385 & 0.35596 & $0.57^{*}$ & 3.60 \\
\hline Error & 6 & 3.72543 & 0.62091 & & 9.41 \\
\hline Total & 26 & 39.58201 & \multicolumn{5}{l}{} \\
\hline
\end{tabular}

$F_{0}$-tabulated for $\alpha=0,05: F_{0}=F_{(2,6)}=5.14$ and $F_{0}=F_{(4,6)}=4.53 ; *$ not significant

\subsection{Confirmation experiment}

Machining responses for initial and optimum setting of cutting parameters are compared in Table VII. The initial setting captures first level of cutting speed $v_{c}$, second level of feed $f$, first level of depth of cut $a_{p}$, and MQL, which is the fourth experiment in the $\mathrm{L}_{27}\left(3^{4}\right)$ Taguchi experimental design. According to the analysis, the optimal solution regarded as a confirmation experiment capture first level of cutting speed $v_{c}$, first level of feed $f$, third level of depth of cut $a_{p}$, and MQL+RHVT cooling method. As shown in Table VII, the average surface roughness $R a$ is improved from $1.653 \mu \mathrm{m}$ to $1.343 \mu \mathrm{m}$, mean roughness depth $R z$ is improved from $8.53 \mu \mathrm{m}$ to $7.15 \mu \mathrm{m}$ and material removal rate $M R R$ is increased from 91000 $\mathrm{mm}^{3} / \mathrm{min}$ to $156000 \mathrm{~mm}^{3} / \mathrm{min}$, however the tool life $T$ is declined from $8.87 \mathrm{~min}$ to $5.35 \mathrm{~min}$.

Table VII: Confirmation experiment results.

\begin{tabular}{|c|c|c|c|c|}
\hline \multirow{2}{*}{ Parameters } & \multirow{2}{*}{ Initial setting } & \multicolumn{2}{|c|}{ Optimal setting } & \multirow{2}{*}{ Improvement } \\
\cline { 3 - 4 } & & Prediction & Experiment & \\
\hline Setting level & $v_{c 1} f_{2} a_{p 1} C_{2}$ & $v_{c 1} f_{1} a_{p 3} C_{3}$ & $v_{c 1} f_{1} a_{p 3} C_{3}$ & \\
\hline$R a(\mu \mathrm{m})$ & 1.653 & & 1.343 & $18.75 \%$ \\
\hline$R z(\mu \mathrm{m})$ & 8.53 & & 7.15 & $16.18 \%$ \\
\hline$T(\mathrm{~min})$ & 8.87 & & 5.35 & $-39.68 \%$ \\
\hline$M R R\left(\mathrm{~mm}^{3} / \mathrm{min}\right)$ & 91000 & & 156000 & $71.43 \%$ \\
\hline$S / N$ ratio & -6.35642 & -4.36061 & -2.86932 & $54.86 \%$ \\
\hline
\end{tabular}

\section{CONCLUSION}

The cutting parameters multi-criteria optimization for the turning of X20Cr13 martensitic stainless steel was carried out. ANOVA showed that the feed and cooling method are the dominant cutting parameters contributing the most to the concurrent minimizing of surface roughness and tool life while maximizing material removal rate. On the subject of the multicriteria optimization problem, it should be pointed out that the Taguchi based entropy weighted GRA is very easy to grasp for practical use in any machine shop.

Furthermore, the combination of MQL with RHVT proved to be the best cooling method. It can be utilized as an efficient alternative to wet machining and MQL alone. Therefore, the use of classic MWFs (i.e. emulsions), when turning martensitic stainless steels, can be excluded. The transition from oil-based MWFs to MQL+RHVT cooling method is a step forward towards sustainable machining, resulting in a significant decrease in the ecological load and in the risk of danger to human health. 
Finally, for better understanding and more comprehensive optimization of aforementioned cooling method, it would be of further interest to establish the mathematical models between the machining responses and cutting speed, feed and depth of cut.

\section{ACKNOWLEDGEMENT}

This work was supported by the University of Rijeka, Croatia, Grant No. uniri-tehnic-18-293.

\section{REFERENCES}

[1] BSSA. General Principles of Machining Stainless Steels, from https://www.bssa.org.uk/topics.php?article $=192$, accessed on 03-07-2018

[2] Atlas Steels. Machining of Stainless Steels, from http://www.atlassteels.com.au/documents/, accessed on 03-07-2018

[3] Markets and Markets. Metalworking Fluids Market, from https://www.marketsandmarkets.com/ Market-Reports/metal-working-fluid-market-116835111.html, accessed on 03-07-2018

[4] EUR-Lex. Document 32000D0532, 2000/532/EC, from https://eur-lex.europa.eu/legalcontent/EN/ALL/? uri=celex\%3A32000D0532, accessed 03-07-2018

[5] EUR-Lex. Document 32008L0098, Directive 2008/98/EC, from https://eur-lex.europa.eu/legalcontent/EN/TXT/? uri=celex\%3A32008L0098, accessed 03-07-2018

[6] Boswell, B.; Islam, M. N.; Davies, I. J.; Ginting, Y. R.; Ong, A. K. (2017). A review identifying the effectiveness of minimum quantity lubrication (MQL) during conventional machining, The International Journal of Advanced Manufacturing Technology, Vol. 92, No. 1-4, 321-340, doi:10.1007/s00170-017-0142-3

[7] Dixit, U. S.; Sarma, D. K.; Davim, J. P. (2012). Environmentally Friendly Machining, Springer, Boston, doi:10.1007/978-1-4614-2308-9

[8] Boswell, B. (2008). Use of Air-cooling and its Effectiveness in Dry Machining Processes, $\mathrm{PhD}$ Thesis, Curtin University, Perth

[9] Ginting, Y. R.; Boswell, B.; Biswas, W. K.; Islam, M. N. (2016). Environmental generation of cold air for machining, Procedia CIRP, Vol. 40, 648-652, doi:10.1016/j.procir.2016.01.149

[10] Taha, Z.; Salaam, H. A.; Tuan Ya, T. M. Y. S.; Phoon, S. Y.; Tan, C. F.; Akiah, M. A. (2013). Vortex tube air cooling: the effect on surface roughness and power consumption in dry turning, International Journal of Automotive and Mechanical Engineering, Vol. 8, 1477-1586, doi:10.15282/ijame.8.2013.34.0122

[11] Liu, N.-M.; Chiang, K.-T.; Hung, C.-M. (2013). Modelling and analyzing the effects of aircooled turning on the machinability of Ti-6Al-4V titanium alloy using the cold air gun coolant system, The International Journal of Advanced Manufacturing Technology, Vol. 67, No. 5-8, 1053-1066, doi:10.1007/s00170-012-4547-8

[12] Sarma, D. K.; Dixit, U. S. (2007). A comparison of dry and air-cooled turning of grey cast iron with mixed oxide ceramic tool, Journal of Materials Processing Technology, Vol. 190, No. 1-3, 160-172, doi:10.1016/j.jmatprotec.2007.02.049

[13] Singh, G.; Sharma, V. S. (2017). Analyzing machining parameters for commercially pure titanium (Grade 2), cooled using minimum quantity lubrication assisted by a Ranque-Hilsch vortex tube, The International Journal of Advanced Manufacturing Technology, Vol. 88, No. 912, 2921-2928, doi:10.1007/s00170-016-8982-9

[14] Deiab, I.; Raza, S. W.; Pervaiz, S. (2014). Analysis of lubrication strategies for sustainable machining during turning of titanium Ti-6Al-4V alloy, Procedia CIRP, Vol. 17, 766-771, doi:10.1016/j.procir.2014.01.112

[15] Fedai, Y.; Kahraman, F.; Kirli Akin, H.; Basar, G. (2018). Optimization of machining parameters in face milling using multi-objective Taguchi technique, Technical Journal, Vol. 12, No. 2, 104108, doi:10.31803/tg-20180201125123

[16] Sekulic, M.; Kovac, P.; Gostimirovic, M.; Kramar, D. (2013). Optimization of high-pressure jet assisted turning process by Taguchi method, Advances in Production Engineering \& Management, Vol. 8, No. 1, 5-12, doi:10.14743/apem2013.1.148 
[17] Deng, J. L. (1989). Introduction to Grey system theory, The Journal of Grey System, Vol. 1, No. $1,1-24$

[18] Puh, F.; Jurkovic, Z.; Cukor, G.; Perinic, M.; Brezocnik, M.; Sekulic, M. (2015). Multi-response optimization of turning parameters using the Grey-based Taguchi method, Journal of Trends in the Development of Machinery and Associated Technology, Vol. 19, No. 1, 13-16

[19] Gupta, M. K.; Sood, P. K. (2015). Optimization of machining parameters for turning AISI 4340 steel using Taguchi based grey relational analysis, Indian Journal of Engineering and Materials Sciences, Vol. 22, No. 6, 679-685

[20] Wen, K.-L.; Chang, T.-C.; You, M.-L. (1998). The grey entropy and its application in weighting analysis, Proceedings of the 1998 IEEE International Conference on Systems, Man, and Cybernetics, 1842-1844

[21] Kumar, S.; Yadav, R. N.; Kumar, R. (2019). Multi-response optimization of duplex turning of Nickel alloy using grey relational analysis with entropy measurement, Engineering Research Express, Vol. 1, No. 2, Paper 025006, 12 pages, doi:10.1088/2631-8695/ab47ab

[22] Grguras, D.; Kramar, D. (2017). Optimization of hybrid manufacturing for surface quality, material consumption and productivity improvement, Strojniski vestnik - Journal of Mechanical Engineering, Vol. 63, No. 10, 567-576, doi:10.5545/sv-jme.2017.4396

[23] D’Mello, G.; Srinivasa Pai, P.; Prashanth, A. (2018). Surface roughness analysis in high speed turning of Ti-6Al-4V using coated carbide inserts: experimental and modelling studies, Tribology in Industry, Vol. 40, No. 3, 457-476, doi:10.24874/ti.2018.40.03.12

[24] De Almeida, F. A.; Gomes, G. F.; de Paula, V. R.; Corrêa, J. É.; de Paiva, A. P.; de Freitas Gomes, J. H.; Turrioni, J. B. (2018). A weighted mean square error approach to the robust optimization of the surface roughness in an AISI 12L14 free-machining steel-turning process, Strojniski vestnik - Journal of Mechanical Engineering, Vol. 64, No. 3, 147-156, doi:10.5545/svjme.2017.4901

[25] Tamerabet, Y.; Brioua, M.; Tamerabet, M.; Khoualdi, S. (2018). Experimental investigation on tool wear behaviour and cutting temperature during dry machining of carbon steel SAE 1030 using KC810 and KC910 coated inserts, Tribology in Industry, Vol. 40, No. 1, 52-65, doi:10.24874/ti.2018.40.01.04

[26] Pusavec, F.; Kopac, J. (2011). Sustainability assessment: cryogenic machining of Inconel 718, Strojniski vestnik - Journal of Mechanical Engineering, Vol. 57, No. 9, 637-647, doi:10.5545/svjme.2010.249

[27] Fuka, J.; Lesakova, P.; Bata, R. (2018). Sustainable value as a tool for performance measurement of the region, Lex Localis - Journal of Local Self-Government, Vol. 16, No. 4, 693-713, doi:10.4335/16.4.693-713(2018)

[28] Chandrasekaran, K.; Marimuthu, P.; Raja, K.; Manimaran, A. (2013). Machinability study on AISI410 with different layered inserts in CNC turning during dry conditions, Indian Journal of Engineering and Materials Sciences, Vol. 20, No. 5, 398-404

[29] Vignesh Kumar, V.; Raja, K.; Marimuthuc, P.; Chandrasekaran, K. (2014). Multi response optimization on AISI 410 and EN 19 steel in turning operation using grey relational analysis, International Journal of Mechanical Engineering and Robotics Research, Vol. 3, No. 2, 121-130

[30] Ahamed Meeran, R.; Chandrasekaran, K.; Thirumalairaj, V.; Radhakrishnan, R. (2014). Performance of tool coated with B-TiC during turning stainless steel, Global Journal of Engineering, Design \& Technology, Vol. 3, No. 6, 1-4

[31] Sobiyi, K.; Sigalas, I. (2015). Optimization in hard turning of martensitic stainless steel using Taguchi method, Proceedings of the $3^{\text {rd }}$ International Conference on Chemical, Civil and Environmental Engineering, 111-115, doi:10.15242/IIE.E0315016

[32] Senthilvelan, N.; Marimuthu, P.; Chandrasekaran, K. (2016). Machining performance of the MSS using BAlN/SiC coated tool, International Journal of ChemTech Research, Vol. 9, No. 5, 402-407

[33] Kovacic, M.; Brezocnik, M. (2018). Reduction of surface defects and optimization of continuous casting of 70MnVS4 steel, International Journal of Simulation Modelling, Vol. 17, No. 4, 667676, doi:10.2507/IJSIMM17(4)457

[34] Nandhakumar, S.; Shanmuga Prakash, R. (2017). Parametric optimization in CNC turning of martensitic stainless steel 416 using Taguchi method, Journal of Chemical and Pharmaceutical Sciences, Vol. 2017, Special Issue 2, 193-198 